\title{
Incidental durotomy in decompression for lumbar spinal stenosis: incidence, risk factors and effect on outcomes in the Spine Tango registry
}

\author{
Christian Herren $^{1} \cdot$ Rolf Sobottke $^{2,3} \cdot$ Anne F. Mannion $^{4} \cdot$ Thomas Zweig $^{5,6}$ • \\ Everard Munting ${ }^{7} \cdot$ Philippe Otten $^{8} \cdot$ Tim Pigott $^{9} \cdot$ Jan Siewe $^{2} \cdot$ Emin Aghayev $^{4}$. \\ On behalf of the Spine Tango Contributors
}

\begin{abstract}
Purpose The three aims of this Spine Tango registry study of patients undergoing decompression for spinal stenosis were to: report the rate of dural tear (DT) stratified by treatment centre; find factors associated with an increased likelihood of incurring a DT; and compare treatment outcomes in relation to DT (none vs. repaired vs. unrepaired DT).

Methods Multivariate logistic regression was used to assess the association between DT and patient and treatment characteristics. Patient-rated and surgical outcomes
\end{abstract}

Christian Herren

cherren@ukaachen.de

1 Department for Trauma and Reconstructive Surgery, University Hospital RWTH Aachen, Pauwelsstraße 30, 52074 Aachen, Germany

2 Department of Orthopaedic and Trauma Surgery, University of Cologne, Joseph-Stelzmann-Straße 9, 50924 Cologne, Germany

3 Department of Orthopaedic Surgery, Medizinisches Zentrum StädteRegion Aachen, Mauerfeldchen 25, 52146 Würselen, Germany

4 Spine Centre Division, Department of Research and Development, Schulthess Klinik, Lengghalde 2, 8008 Zurich, Switzerland

5 Spinecenter, Schänzlistrasse 39, 3025 Bern, Switzerland

6 Institute for Social and Preventive Medicine, Finkenhubelweg 11, 3012 Bern, Switzerland

7 Clinique Saint Pierre, Av. Reine Fabiola 9, 1340 Ottignies, Belgium

8 Clinique Générale de Fribourg, Rue Hans-Geiler 6, 1700 Fribourg, Switzerland

9 Department of Neurosurgery, Walton Centre for Neurosurgery, Lower Lane, L9 7LJ Liverpool, UK were compared in patients with no DT, repaired DT, and unrepaired DT, while adjusting for case-mix. Results DT occurred in 328/3254 (10.1\%) of included patients. The rate for all 29 contributing hospitals was within $95 \%$ confidence intervals of the average. The likelihood of DT increased by $2 \%$ per year of age, 1.78 times with previous spine surgery, 1.67 for a minimally/less invasive surgery, 1.58 times with laminectomy, and 1.40, and 2.12 times for BMI 31-35, and $>35$ in comparison with BMI 26-30, respectively. The majority of DTs (272/ $328 ; 82.9 \%)$ were repaired. Repairing the DT was associated with a longer duration of surgery $(p<0.001)$. More patients with repaired than with unrepaired DTs were satisfied with treatment, but the difference was not statistically significant. There was no association between DT and patient-reported outcomes.

Conclusion The unadjusted rate of incidental DT during decompression for LSS was homogeneous across the participating centres and was associated with age, BMI, previous surgery at the same spinal level, minimally/less invasive surgery, and laminectomy. Non-repair of DTs had no negative association with treatment outcome; however, the unrepaired DTs may have been those that were smaller in size.

Keywords Spine Tango registry · Lumbar spinal stenosis . Decompression · Durotomy · Outcome

\section{Introduction}

More than $40 \%$ of spine surgeries in the international spine registry, Spine Tango, are for lumbar spinal stenosis (LSS) [1], with the established surgical procedure being open posterior decompression with or without fusion. 
Incidental tearing of the dural sac is one of the most common complications associated with the procedure. Depending on the precise intervention, incidental durotomy (DT) rates as high as $17 \%$ have been reported [2-5]. DT rates in the studies from the Spine Patient Outcome Research Trial (SPORT), Spine Tango, and the Swespine registry range between 7.4 and $9.0 \%$ [5-7]. Risk factors for DT are well known: patient age, previous surgery, obesity, number of treated levels, and degree of surgical invasiveness [7-10].

The intraoperative management of DT is the subject of debate. Intraoperative suturing of a lesion with or without additional fibrin glue seems to be the preferred procedure $[11,12]$, though other alternatives to suturing exist, including fascia patches, fat or muscle grafts with or without fibrin glue, and other closure options such as direct coverage with artificial sleeves [13-15]. However, the literature provides no clear consensus or recommendations on DT management, and it may depend on the accessibility, location, and size of the lesion. Each surgeon generally uses his/her own repair procedure based on his/her own experience. The consequences of a DT include headache, nausea, vomiting, vertigo, persistent cerebrospinal fluid (CSF) leak, fistula or pseudomeningocele, wound healing disorders, infection, meningitis, or intracerebral bleeding, and, in the worst case, cerebellar tonsil herniation as a lethal complication $[3,4,16-18]$.

At least two studies have demonstrated no effect of incidental DT on surgical and patient-reported outcomes. A study of the SPORT data reported no effect of incidental DT on wound complications, early mortality, or long-term patient-rated outcome, though the overall length of stay, duration of surgery, and intraoperative blood loss were all higher for patients with a DT [19]. Analysis of Swespine registry data similarly demonstrated no effect of DT on 1-year patient-rated outcomes [7]. These studies were limited geographically to one country only and accounted for only few potential confunders.

The aim of the present study was to use data from the international Spine Tango registry to: (1) examine the rate of incidental DT in open decompression for spinal stenosis, stratified by treatment centre, (2) analyse factors associated with DT and (3) compare outcomes amongst patients with no DT, repaired DT, and unrepaired DT, while adjusting for case-mix.

\section{Materials and methods}

The study was carried out using the Spine Tango data pool and written in accordance with the STROBE guidelines [20].

\section{Spine Tango}

Spine Tango is the international spine registry of Eurospine, the Spine Society of Europe, in which patient and physician-based data are collected on a prospective basis [21]. We used the current Spine Tango surgery form (version 2011; http://www.eurospine.org/forms.htm), which records data on patient demographics, pathology, indication for treatment, previous treatments, and surgical details. Patient-rated outcome data were collected using the Spine Tango "Patient self-assessment form" (http://www. eurospine.org/forms.htm) which includes the Core Outcome Measures Index (COMI) questionnaire [22] (completed pre and postoperatively) and single item outcome questions (completed postoperatively only) enquiring about the following: the global treatment outcome ("overall, how much did the operation that you received help your back problem?") with five response options (helped a lot, helped, helped only little, did not help, made things worse); further spine surgery (none, different level, same level); and patient satisfaction with treatment in the hospital (very satisfied, satisfied, neither satisfied nor dissatisfied, dissatisfied, very dissatisfied). In the analyses, global treatment outcome was dichotomized into "good" (helped a lot + helped) and "poor" (helped only little + did not help + made things worse); further surgery, into "reoperation at the same level" and "no reoperation at the same level"; and patient satisfaction, into "satisfied" (very satisfied + satisfied) and "not satisfied" (very dissatisfied + dissatisfied + neither satisfied nor dissatisfied).

\section{Inclusion criteria}

Between January 2011 and March 2017, 54,413 patients were documented in Spine Tango from 15 countries. Patients in Finland, India, Moldova, Netherlands, Singapore, Slovenia, Taiwan, and Turkey were not considered in the present study due to the lack of a validated language version of the COMI. For the remaining 52,291 patients in Australia, Belgium, Germany, Poland, Switzerland, UK, and USA, further inclusion criteria were applied to identify patients undergoing posterior decompression only for spinal stenosis, with additional conditions regarding the availability of accompanying data such as BMI, comorbidity, patient-questionnaires, as listed in Fig. 1. If multiple surgeries were available for a patient, only the first dated surgery was considered. If multiple follow-up forms were available for a patient within the given follow-up period, the most recent data form was selected for analysis. Application of these selection criteria resulted in 3254 LSS patients who were eligible for inclusion in the study. 
Fig. 1 Selection algorithm and proportions of excluded patients by selection criterion

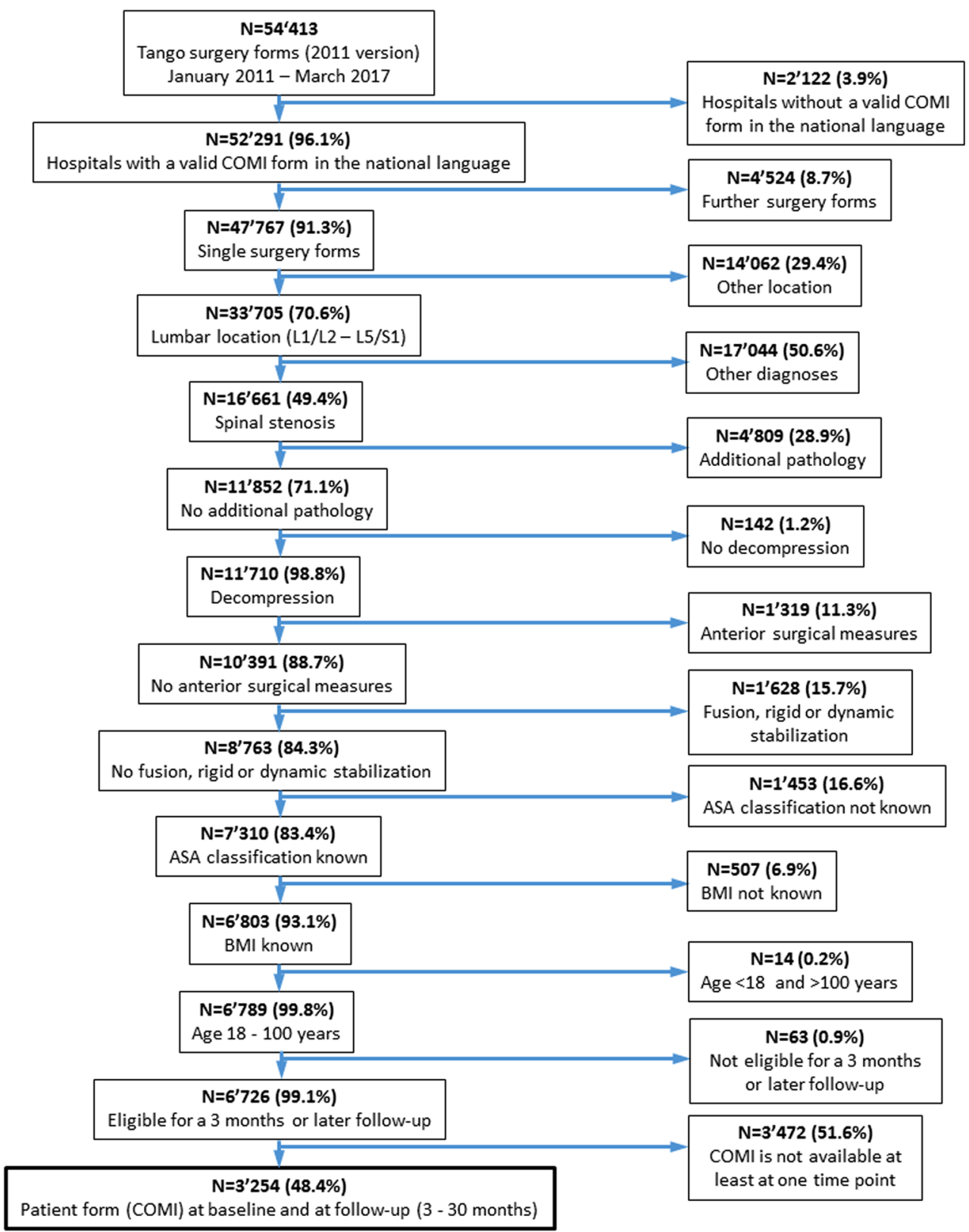

\section{Statistical analyses}

\section{Unadjusted rates of DT}

The unadjusted DT rate was calculated for each treatment centre and plotted against the number of documented surgeries in a funnel plot. The $95 \%$ confidence intervals $(95 \% \mathrm{CI})$ were included around the overall average DT rate.

\section{Risk factors for DT}

Comparisons of patient and treatment characteristics between those patients with and without incidental DT were performed using the Chi-square test for nominal data and the Wilcoxon rank-sum test for continuous data.

The analysis of statistical predictors for incurring a DT was carried out using multivariate logistic regression analysis. The following covariates were included in the model: patient age (continuous) and sex (male, female), BMI category $(<20,20-25,26-30,31-35,>35)$, smoking status (smoker, nonsmoker, unknown), previous treatment (none, surgical, $<6$ months conservative, 6-12 months conservative, $>12$ months conservative), ASA status $(1,2$, 2), segment (L1/2-L2/3, L3/4, L4/5, L5/S1), extent of lesion (1 segment, $2-3$ segments, $>3$ segments), number of previous spine surgeries (continuous), previous spine surgery on the same level (yes, no), surgeon experience (board 
certified, in training), minimally/less invasive surgical approach (yes/no), discectomy (yes, no), laminotomy (yes, no), hemilaminectomy (yes, no), laminectomy (yes, no), facet joint resection partial or full (yes, no), flavectomy (yes, no), foraminotomy (yes, no), and other decompression (yes, no). A stepwise selection algorithm was used and second-order interactions were assessed.

\section{No DT, repaired and unrepaired DT}

The study sample of 3254 patients was subdivided into three groups: 2926 (89.9\%) patients without DT; 272 $(8.4 \%)$ patients with DT, repaired using fibrin glue and/or suture $(n=268)$, fat graft $(n=3)$, fascia patch $(n=2)$, Duragen $(n=1)$, clip $(n=1)$, or Spongostan $(n=1)$; and $56(1.7 \%)$ patients whose DT was not repaired.

Eleven outcome measures were assessed in these groups: duration of surgery, postoperative cranial complication, CSF leak, superficial or deep infection, back pain relief, leg pain relief, COMI score improvement, patientreported reoperations at the same vertebral level, patient satisfaction with treatment in the hospital, patient assessment of the global treatment outcome, and length of postoperative hospital stay (LOS) (days between operation date and discharge date).

The inverse probability of treatment weighting (IPTW) using the propensity score was applied to balance the three patient groups for their patient and treatment characteristics. This method uses weights based on the propensity score to create a synthetic sample in which the distribution of measured baseline and treatment covariates is independent of the group assignment. In this way the patient groups are made similar to each other and outcome measures can be compared between similar patients. The propensity score was estimated without regard to outcome variables using multiple logistic regression analysis. The abovementioned covariates and, additionally, back pain, leg pain, and COMI score at baseline and follow-up (all continuous) were included in the propensity score. Bivariate comparison of patient characteristics in the patient groups before and after weighting adjustment was performed using general linear modelling or the Chi square test as appropriate. The level of significance was set to 0.05 throughout the study. All statistical analyses were conducted using SAS 9.4 (SAS Institute Inc., Cary, NC, USA).

\section{Results}

\section{Unadjusted rates of DT}

In total, there were $328 / 3254(10.1 \%)$ intraoperative DTs (Table 1). DT rates varied between treatment centres with different numbers of documented operative procedures. Overall, 21 out of 29 centres reported a DT. None of the centres had a DT rate beyond the $95 \%$ CI for the average (Fig. 2).

Seven out of the twenty-one centres documented an unrepaired DT with the average rate of unrepaired vs. all DTs in those seven centres being $24.2 \%$ (range $7.1-41.9 \%$ ). The remaining 21 centres had five or fewer DTs each, which all were repaired. Seven out of twentyone centres documented an unrepaired DT with the average rate of unrepaired vs. all DTs in those seven centres being $24.2 \%$ (range $7.1-41.9 \%$ ). The remaining 21 centres had five or fewer DTs each, which all were repaired.

\section{Risk factors for DT}

Demographic and clinical characteristics of the patients with and without DT are summarized in Table 1. Bivariate, unadjusted analyses revealed that, compared with patients with no DT, patients with DT were on average 2.5 years older; more often had an ASA $>2$; more often had a BMI >30 and less often 26-30; had previously undergone a greater number of spine surgeries overall; had previously undergone a greater number of spine surgeries at the same level; more often had two or more involved segments; more often had been operated on with a minimally/less invasive surgical approach; and had more often undergone laminectomy and less often, discectomy. Other characteristics did not differ significantly between the groups.

The multivariate analysis demonstrated that age, BMI, previous surgery at the same level, minimally/less invasive surgery, and laminectomy were significantly associated with the occurrence of DT. According to the model, the likelihood of a DT increased by $2 \%$ per year of age, by a factor of 1.78 with prior surgery at the same level, by a factor of 1.67 with minimally/less invasive surgery, by a factor of 1.58 with laminectomy, and by factors of 1.40 , and 2.12 for BMI 31-35, and $>35$ each in comparison with BMI 26-30 (Table 2).

\section{IPTW adjustment for no DT, repaired DT and unrepaired DT}

The three groups (no DT, repaired DT and unrepaired DT) were successfully balanced for their patient and treatment characteristics ( $p \geq 0.26$; Table 3 ). Patients with repaired DT had a longer duration of surgery than patients with unrepaired DT or those without DT (Table 4). Furthermore, patients with repaired DT had a higher rate of cerebral complications and a longer hospital stay than patients without DT. Finally, patients without DT had a lower rate of CSF leak than each of the groups with DT (Table 4). 
Table 1 Demographic and treatment characteristics of patients with and without dural tear (DT)

\begin{tabular}{|c|c|c|c|}
\hline Patient characteristics & DT, $n=328(10.1 \%)$ & No DT, $n=2926(89.9 \%)$ & Comparison ( $p$ value) \\
\hline Mean age \pm SD (years) & $67.1 \pm 12.4$ & $64.6 \pm 13.1$ & $<0.001$ \\
\hline Female $(\%)$ & 45.7 & 45.2 & 0.84 \\
\hline $\mathrm{BMI}<20(\%)$ & 3.7 & 2.5 & $<0.001$ \\
\hline BMI 20-25 (\%) & 25.0 & 26.2 & \\
\hline BMI 26-30 (\%) & 34.8 & 43.1 & \\
\hline BMI 31-35 (\%) & 24.1 & 21.0 & \\
\hline $\mathrm{BMI}>35(\%)$ & 12.5 & 7.3 & \\
\hline Current smoker $(\%)$ & 9.8 & 12.5 & 0.36 \\
\hline Not-smoker $(\%)$ & 67.1 & 65.0 & \\
\hline Smoking status unknown (\%) & 23.2 & 22.5 & \\
\hline No previous treatment $(\%)$ & 19.2 & 20.9 & 0.76 \\
\hline Previous surgical treatment (\%) & 2.4 & 3.5 & \\
\hline$<6$ months conservative treatment $(\%)$ & 28.4 & 28.3 & \\
\hline $6-12$ months conservative treatment $(\%)$ & 23.2 & 22.5 & \\
\hline$>12$ months conservative treatment $(\%)$ & 26.8 & 24.8 & \\
\hline ASA $1(\%)$ & 17.1 & 22.1 & 0.017 \\
\hline ASA $2(\%)$ & 61.3 & 61.4 & \\
\hline $\mathrm{ASA}>2(\%)$ & 21.7 & 16.5 & \\
\hline $\mathrm{L} 1 / 2-\mathrm{L} 2 / 3(\%)$ & 6.4 & 7.1 & 0.33 \\
\hline $\mathrm{L} 3 / 4(\%)$ & 23.5 & 21.6 & \\
\hline $\mathrm{L} 4 / 5(\%)$ & 53.4 & 50.6 & \\
\hline L5/S1 (\%) & 16.8 & 20.8 & \\
\hline 1 segment involved (\%) & 49.7 & 55.2 & 0.011 \\
\hline $2-3$ segments involved $(\%)$ & 43.0 & 40.4 & \\
\hline$>3$ segments involved $(\%)$ & 7.3 & 4.4 & \\
\hline Number of previous spine surgeries \pm SD $(n)$ & $1.3 \pm 0.6$ & $1.2 \pm 0.6$ & $\mathbf{0 . 0 2 0}$ \\
\hline Previous spine surgery on the same level (\%) & 15.1 & 10.0 & 0.028 \\
\hline Board-certified surgeon $(\%)$ & 86.0 & 84.2 & 0.40 \\
\hline Surgeon in training $(\%)$ & 14.0 & 15.8 & \\
\hline Minimally/less invasive surgical approach (\%) & 14.3 & 10.5 & $\mathbf{0 . 0 3 3}$ \\
\hline Discectomy $(\%)$ & 16.2 & 24.3 & 0.001 \\
\hline Laminotomy (\%) & 39.3 & 44.1 & 0.10 \\
\hline Hemilaminectomy (\%) & 14.0 & 11.7 & 0.21 \\
\hline Laminectomy (\%) & 34.8 & 25.2 & $<0.001$ \\
\hline Facet joint resection partial or full (\%) & 45.7 & 45.2 & 0.84 \\
\hline Flavectomy $(\%)$ & 63.7 & 64.2 & 0.87 \\
\hline Foraminotomy (\%) & 40.6 & 40.9 & 0.89 \\
\hline Other decompression (\%) & 18.6 & 18.8 & 0.93 \\
\hline
\end{tabular}

Significant differences are highlighted in bold

Both before and after IPTW adjustment, the differences in pain relief and in COMI score improvement (Fig. 3) among the groups were not statistically significant $(p>0.41)$. Other outcomes, including the proportion of patients that were satisfied with the treatment and the global treatment outcome, were not significantly different ( $p \geq 0.10$; Table 4), although the proportions of "not satisfied" patients and patients reporting a "poor" global outcome, respectively, were 9 and $8 \%$ higher in the unrepaired DT group than in either of the other two groups (Table 4).

\section{Discussion}

The major findings of this study were: (1) the overall incidence of DT during decompression surgery for LSS was $10.1 \%$; (2) all centres within the registry were within 
Fig. 2 Unadjusted rates of DT for the individual treatment centres by number of documented surgeries

Table 2 Summary of the multivariate logistic regression analysis of predictors for DT

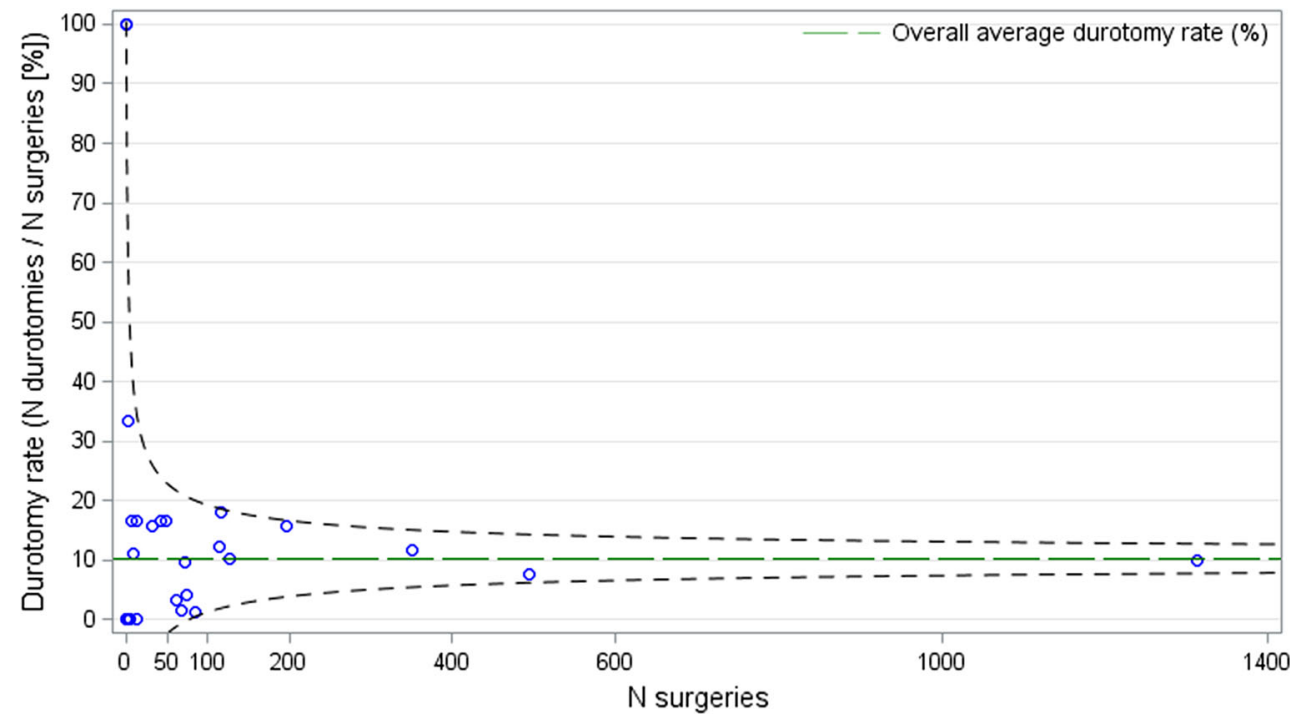

\begin{tabular}{lllr}
\hline Patient or treatment characteristics & Effect & Odds ratio with 95\% CI & $p$ value \\
\hline Previous surgery at the same spinal level & Yes vs. no & $1.78(1.28-2.49)$ & $<0.001$ \\
Laminectomy & Yes vs. no & $1.58(1.23-2.05)$ & $<0.001$ \\
BMI & $<20$ vs. $26-30 \mathrm{~kg} \mathrm{~m}^{-2}$ & $1.79(0.93-3.42)$ & 0.002 \\
& $21-25$ vs. $26-30 \mathrm{~kg} \mathrm{~m}^{-2}$ & $1.17(0.86-1.58)$ & \\
& $31-35$ vs. $26-30 \mathrm{~kg} \mathrm{~m}^{-2}$ & $1.40(1.03-1.89)$ & \\
& $>35$ vs. $26-30 \mathrm{~kg} \mathrm{~m}^{-2}$ & $2.12(1.44-3.13)$ & \\
Age & Per year & $1.02(1.01-1.03)$ & 0.002 \\
Minimal/less invasive surgical approach & Yes vs. no & $1.67(1.18-2.36)$ & 0.004 \\
\hline $95 \% C I 95 \%$ confidence intervals & & &
\end{tabular}

95\% CI 95\% confidence intervals the $95 \% \mathrm{CI}$ for the average value; (3) independent predictors for incidental DT were greater age, BMI $>30$, previous surgery at the same level, a minimally/less invasive surgical approach, and laminectomy; (4) DTs that were not repaired were associated only with a shorter duration of surgery than the repaired ones; (5) the groups did not differ significantly in relation to patient-reported outcomes, although potentially clinically important group differences were observed in the proportion of patients reporting that they were satisfied with the treatment and had a "good" global treatment outcome (with fewer in the DT-unrepaired group).

\section{Clinical implications}

Voluntary, non-monitored medical registries are criticised for a risk of selection bias favouring successful cases and underreporting complications. However, the $10.1 \%$ incidence of DT in our study was higher than that reported for a similar patient population in the Swespine registry (7.4\%) [7], the data quality of which is generally well regarded. Our rate was also slightly higher than those of other good quality studies, including the SPORT [3, 19]. This suggests that systematic underreporting of durotomies in Spine Tango is unlikely. An underreporting of complications in any individual treatment centre in our study sample is also unlikely because none demonstrated a DT rate below the overall mean within the $95 \%$ CI. Also, no outlier above the 95\% CI was found, indicating a fairly homogeneous reporting of DTs across the individual treatment centres. The greater variation in DT rates in low throughput centres can be attributed to a greater variation in patient and treatment characteristics. Their larger confidence intervals also suggest a higher degree of uncertainty. However, only raw (not adjusted) rates were calculated for the individual treatment centres. A more accurate presentation of the variation in adjusted DT rates between the individual centres would require evaluation in a separate study using a hierarchical modelling approach. The multinational character of the data further reinforces the generalizability of the rate of $10.1 \%$ for DTs in decompression for lumbar spinal stenosis. Good registry data capture real-life clinical practice with high external validity [23].

In a large cohort study of patients undergoing surgery for LSS, age was shown to be associated with the incidence of DT [8, 10, 24]. However, a recent retrospective analysis 
Table 3 Patient and treatment characteristics before and after the IPTW adjustment in patient groups

\begin{tabular}{|c|c|c|c|c|c|c|c|c|}
\hline \multirow{3}{*}{$\begin{array}{l}\text { Patient and treatment } \\
\text { characteristics }\end{array}$} & \multicolumn{4}{|c|}{ Before weighting adjustment } & \multicolumn{4}{|c|}{ After weighting adjustment } \\
\hline & \multicolumn{3}{|l|}{ DT } & \multirow{2}{*}{$\begin{array}{l}\text { Comparison } \\
(p \text { value })\end{array}$} & \multicolumn{3}{|l|}{ DT } & \multirow{2}{*}{$\begin{array}{l}\text { Comparison } \\
\text { ( } p \text { value })\end{array}$} \\
\hline & $\begin{array}{l}\text { Repaired, } \\
n=272 \\
(8.4 \%)\end{array}$ & $\begin{array}{l}\text { Unrepaired, } \\
n=56 \\
(1.7 \%)\end{array}$ & $\begin{array}{l}\text { None, } \\
n=2926 \\
(89.9 \%)\end{array}$ & & $\begin{array}{l}\text { Repaired, } \\
n=167 \\
(8.0 \%)\end{array}$ & $\begin{array}{l}\text { Unrepaired, } \\
n=32 \\
(1.5 \%)\end{array}$ & $\begin{array}{l}\text { None, } \\
n=1882 \\
(90.4 \%)\end{array}$ & \\
\hline $\begin{array}{l}\text { Mean age } \\
\quad(\text { years } \pm \mathrm{SD})\end{array}$ & $67.4 \pm 12.3$ & $66.0 \pm 12.6$ & $64.6 \pm 13.1$ & 0.003 & $64.1 \pm 13.6$ & $65.4 \pm 11.1$ & $64.9 \pm 13.0$ & 0.58 \\
\hline Female $(\%)$ & 45.6 & 46.4 & 45.2 & 0.97 & 43.2 & 36.3 & 45.2 & 0.38 \\
\hline $\mathrm{BMI}<20(\%)$ & 2.9 & 7.1 & 2.5 & 0.002 & 2.2 & 3.6 & 2.6 & 0.99 \\
\hline BMI 20-25 (\%) & 23.9 & 30.4 & 26.2 & & 26.0 & 23.1 & 26.1 & \\
\hline BMI 26-30 (\%) & 35.3 & 32.1 & 43.1 & & 43.2 & 37.9 & 42.2 & \\
\hline BMI 31-35 (\%) & 25.7 & 16.1 & 21.0 & & 20.6 & 27.1 & 21.3 & \\
\hline $\mathrm{BMI}>35(\%)$ & 12.1 & 14.3 & 7.3 & & 8.0 & 8.3 & 7.8 & \\
\hline Current smoker (\%) & 9.2 & 12.5 & 12.5 & 0.59 & 12.0 & 7.1 & 12.2 & 0.80 \\
\hline Not-smoker (\%) & 66.9 & 67.9 & 65.0 & & 63.7 & 68.5 & 65.2 & \\
\hline $\begin{array}{r}\text { Smoking status } \\
\text { unknown }(\%)\end{array}$ & 23.9 & 19.6 & 22.5 & & 24.3 & 24.4 & 22.6 & \\
\hline $\begin{array}{l}\text { No previous treatment } \\
(\%)\end{array}$ & 15.8 & 35.7 & 20.9 & 0.043 & 21.8 & 26.2 & 20.8 & 0.96 \\
\hline $\begin{array}{l}\text { Previous surgical } \\
\text { treatment }(\%)\end{array}$ & 1.8 & 5.4 & 3.5 & & 3.7 & 1.5 & 3.4 & \\
\hline $\begin{array}{l}<6 \text { months } \\
\text { conservative } \\
\text { treatment }(\%)\end{array}$ & 29.4 & 23.2 & 28.3 & & 27.6 & 21.6 & 28.3 & \\
\hline $\begin{array}{l}6-12 \text { months } \\
\text { conservative } \\
\text { treatment }(\%)\end{array}$ & 24.6 & 16.1 & 22.5 & & 22.8 & 26.7 & 22.6 & \\
\hline $\begin{array}{l}>12 \text { months } \\
\text { conservative } \\
\text { treatment }(\%)\end{array}$ & 28.3 & 19.6 & 24.8 & & 24.2 & 24.0 & 25.0 & \\
\hline ASA $1(\%)$ & 16.2 & 21.4 & 22.1 & 0.041 & 22.6 & 18.2 & 21.6 & 0.91 \\
\hline ASA $2(\%)$ & 61.0 & 62.5 & 61.4 & & 61.5 & 61.0 & 61.5 & \\
\hline ASA >2(\%) & 22.8 & 16.1 & 16.5 & & 16.0 & 20.8 & 17.0 & \\
\hline $\mathrm{L} 1 / 2-\mathrm{L} 2 / 3(\%)$ & 6.6 & 5.4 & 7.1 & 0.23 & 6.9 & 4.3 & 7.0 & 0.83 \\
\hline $\mathrm{L} 3 / 4(\%)$ & 24.3 & 19.6 & 21.6 & & 20.2 & 18.4 & 21.8 & \\
\hline L4/5 (\%) & 50.7 & 66.1 & 50.6 & & 52.1 & 61.6 & 50.8 & \\
\hline L5/S1 (\%) & 18.4 & 8.9 & 20.8 & & 20.8 & 15.8 & 20.3 & \\
\hline $\begin{array}{l}1 \text { segment involved } \\
(\%)\end{array}$ & 49.3 & 51.8 & 55.2 & 011 & 53.2 & 64.1 & 54.7 & 0.68 \\
\hline $\begin{array}{l}2-3 \text { segments } \\
\text { involved }(\%)\end{array}$ & 43.4 & 41.1 & 40.4 & & 42.5 & 31.4 & 40.6 & \\
\hline $\begin{array}{l}>3 \text { segments involved } \\
(\%)\end{array}$ & 7.4 & 7.1 & 4.4 & & 4.4 & 4.5 & 4.7 & \\
\hline $\begin{array}{l}\text { Number of previous } \\
\text { spine surgeries } \\
(n \pm \mathrm{SD})\end{array}$ & $1.3 \pm 0.6$ & $1.3 \pm 0.7$ & $1.2 \pm 0.6$ & 0.040 & $1.2 \pm 0.5$ & $1.2 \pm 0.5$ & $1.2 \pm 0.6$ & 0.89 \\
\hline $\begin{array}{l}\text { Previous spine surgery } \\
\text { on the same level } \\
(\%)\end{array}$ & 15.8 & 10.7 & 9.3 & 0.003 & 10.3 & 11.8 & 9.8 & 0.88 \\
\hline $\begin{array}{l}\text { Board-certified } \\
\text { surgeon }(\%)\end{array}$ & 84.6 & 92.9 & 84.2 & 0.21 & 84.3 & 89.1 & 84.3 & 0.67 \\
\hline $\begin{array}{l}\text { Surgeon in training } \\
(\%)\end{array}$ & 15.4 & 7.1 & 15.8 & & 15.7 & 11.0 & 15.7 & \\
\hline
\end{tabular}


Table 3 continued

\begin{tabular}{|c|c|c|c|c|c|c|c|c|}
\hline \multirow{3}{*}{$\begin{array}{l}\text { Patient and treatment } \\
\text { characteristics }\end{array}$} & \multicolumn{4}{|c|}{ Before weighting adjustment } & \multicolumn{4}{|c|}{ After weighting adjustment } \\
\hline & \multicolumn{3}{|l|}{ DT } & \multirow{2}{*}{$\begin{array}{l}\text { Comparison } \\
(p \text { value })\end{array}$} & \multicolumn{3}{|l|}{ DT } & \multirow{2}{*}{$\begin{array}{l}\text { Comparison } \\
\text { ( } p \text { value) }\end{array}$} \\
\hline & $\begin{array}{l}\text { Repaired, } \\
n=272 \\
(8.4 \%)\end{array}$ & $\begin{array}{l}\text { Unrepaired, } \\
n=56 \\
(1.7 \%)\end{array}$ & $\begin{array}{l}\text { None, } \\
n=2926 \\
(89.9 \%)\end{array}$ & & $\begin{array}{l}\text { Repaired, } \\
n=167 \\
(8.0 \%)\end{array}$ & $\begin{array}{l}\text { Unrepaired, } \\
n=32 \\
(1.5 \%)\end{array}$ & $\begin{array}{l}\text { None, } \\
n=1882 \\
(90.4 \%)\end{array}$ & \\
\hline Discectomy (\%) & 16.9 & 12.5 & 24.3 & 0.003 & 22.9 & 17.7 & 23.5 & 0.62 \\
\hline Laminotomy (\%) & 37.1 & 50.0 & 44.1 & 0.053 & 42.0 & 40.8 & 43.6 & 0.81 \\
\hline $\begin{array}{l}\text { Hemilaminectomy } \\
(\%)\end{array}$ & 15.1 & 8.9 & 11.7 & 0.20 & 11.9 & 11.1 & 11.9 & 0.99 \\
\hline Laminectomy (\%) & 35.7 & 30.4 & 25.2 & $<0.001$ & 25.7 & 31.3 & 26.2 & 0.70 \\
\hline $\begin{array}{l}\text { Facet joint resection } \\
\text { partial or full }(\%)\end{array}$ & 46.3 & 42.9 & 45.2 & 0.88 & 42.7 & 34.8 & 45.2 & 0.26 \\
\hline Flavectomy (\%) & 63.6 & 64.3 & 64.2 & 0.98 & 64.8 & 66.9 & 64.1 & 0.91 \\
\hline Foraminotomy (\%) & 41.5 & 35.7 & 40.9 & 0.71 & 42.1 & 43.7 & 40.9 & 0.86 \\
\hline $\begin{array}{l}\text { Other decompression } \\
(\%)\end{array}$ & 20.2 & 10.7 & 18.8 & 0.25 & 17.3 & 12.7 & 18.7 & 0.47 \\
\hline $\begin{array}{l}\text { Back pain } \\
\text { baseline } \pm \mathrm{SD} \\
\text { (points) }\end{array}$ & $5.8 \pm 2.9$ & $6.5 \pm 2.4$ & $5.9 \pm 2.9$ & 0.26 & $5.9 \pm 2.9$ & $6.3 \pm 2.3$ & $5.9 \pm 2.9$ & 0.61 \\
\hline $\begin{array}{l}\text { Leg pain } \\
\text { baseline } \pm \mathrm{SD} \\
\text { (points) }\end{array}$ & $7.2 \pm 2.4$ & $7.4 \pm 2.2$ & $7.2 \pm 2.4$ & 0.93 & $7.2 \pm 2.4$ & $7.3 \pm 1.9$ & $7.2 \pm 2.4$ & 0.96 \\
\hline $\begin{array}{l}\text { COMI score } \\
\text { baseline } \pm \mathrm{SD} \\
\text { (points) }\end{array}$ & $7.6 \pm 1.6$ & $7.8 \pm 1.7$ & $7.7 \pm 1.7$ & 0.80 & $7.7 \pm 1.6$ & $7.8 \pm 1.6$ & $7.7 \pm 1.7$ & 0.80 \\
\hline $\begin{array}{l}\text { COMI interval } \pm \text { SD } \\
\text { (months) }\end{array}$ & $14.9 \pm 8.3$ & $16.9 \pm 8.2$ & $15.4 \pm 8.3$ & 0.25 & $15.2 \pm 8.5$ & $15.0 \pm 7.5$ & $15.4 \pm 8.3$ & 0.89 \\
\hline
\end{tabular}

$D T$ durotomy, $S D$ standard deviation

Significant differences are written in bold

of 563 patients did not confirm this [25]. Obesity, too, has been associated with a higher incidence of DT in lumbar spine surgery [9]. Our results showed that, compared with BMI 26-30, higher ( $>30$ ) BMI scores had a significant association with the incidence of intraoperative DT. Higher BMI ( $>30)$ is a widely accepted risk factor for complications during spinal surgery $[9,26]$. The explanation for this association resides in the difficulty of surgical exposure due to the greater volume of soft tissue and the depth of the incision.

In our study, the likelihood for a DT increased by $67 \%$ if a minimally/less invasive surgical approach was used. Teli et al. found in a randomized trial clearly higher DT rate in micro-endoscopic surgeries than in surgeries using microscope only or in an open discectomy $(8.7,2.7$ and 3.0\%, respectively) [27]. However, this difference was not statistically significant. Similar to the association with obesity, the explanation for this finding may also lie in the difficulty of access with a minimally or less invasive approach, and poor perception of depth [27]. The fact that the 95\% CI for this finding were rather narrow (1.18-2.36) suggests that this is a reliable estimate. We also found a significant association of laminectomy with DT, which appears reasonable for this invasive decompression close to the dura. Deyo et al. also found laminectomy to be associated with a higher incidence of DT [10].

Several studies have demonstrated that previous surgery at the same level is an important risk factor for incidental DT $[8,28]$. Scar tissue that adheres to the dura and complicates the surgical differentiation between the two may explain this association. Odds ratios of 2.21 and 4.78, respectively, have been reported by others for the occurrence of DT in patients undergoing revision surgery $[8,28]$. Our odds ratio was 1.78 . The origin of the differences in the precise association between revision surgery and occurrence of DT may lie in different patient populations or reporting accuracy.

The rate of patient-reported reoperations at the same vertebral level was not different between the groups. There is little evidence in the recent literature on reoperation rates after incidental DT. A relatively small study by Grannum et al. showed no reoperations in 14 unrepaired DT cases and concluded that DT in LSS surgery can be managed without repair with no negative effect on surgical outcome [29]. 
Table 4 IPTW adjusted outcomes in the patient groups

\begin{tabular}{|c|c|c|c|c|c|c|}
\hline \multirow{2}{*}{$\begin{array}{l}\text { Patient and treatment } \\
\text { characteristics }\end{array}$} & \multicolumn{3}{|l|}{ Dura lesion } & \multirow{2}{*}{$\begin{array}{l}\text { Repaired vs. } \\
\text { unrepaired DT } \\
\text { ( } p \text { value })\end{array}$} & \multirow{2}{*}{$\begin{array}{l}\text { Repaired vs. no } \\
\text { DT ( } p \text { value) }\end{array}$} & \multirow{2}{*}{$\begin{array}{l}\text { Unrepaired vs. } \\
\text { no DT ( } p \text { value })\end{array}$} \\
\hline & $\begin{array}{l}\text { Repaired DT, } \\
n=272 \\
(8.02 \%)\end{array}$ & $\begin{array}{l}\text { Unrepaired DT, } \\
n=56(1.54 \%)\end{array}$ & $\begin{array}{l}\text { No DT, } \\
n=2926 \\
(90.44 \%)\end{array}$ & & & \\
\hline $\begin{array}{l}\text { Surgery time: unknown } \\
(\%)\end{array}$ & 0.6 & - & 0.6 & $<0.001$ & $<0.001$ & 0.53 \\
\hline Surgery time: $<1 \mathrm{~h}(\%)$ & 17.6 & 47.6 & 34.2 & & & \\
\hline Surgery time: $1-2 \mathrm{~h}(\%)$ & 54.7 & 44.5 & 56.8 & & & \\
\hline Surgery time: $2-3 \mathrm{~h}(\%)$ & 20.9 & 4.8 & 7.2 & & & \\
\hline Surgery time: $>3 \mathrm{~h}(\%)$ & 6.2 & 3.2 & 1.2 & & & \\
\hline Cerebral complication (\%) & 0.8 & - & 0.1 & 1.0 & 0.003 & 1.0 \\
\hline CSF leak (\%) & 3.2 & 9.2 & 0.1 & 0.15 & $<0.001$ & $<0.001$ \\
\hline Superficial infection (\%) & - & - & 0.3 & - & 1.0 & 1.0 \\
\hline Deep infection (\%) & - & - & 0.2 & - & 1.0 & 1.0 \\
\hline $\begin{array}{l}\text { Back pain postop } \pm \text { SD } \\
\text { (points) }\end{array}$ & $4.2 \pm 3.1$ & $3.7 \pm 2.8$ & $3.8 \pm 3.1$ & 0.87 & 0.26 & 1.0 \\
\hline $\begin{array}{l}\text { Back pain relief } \pm S D \\
\text { (points) }\end{array}$ & $1.7 \pm 3.0$ & $2.6 \pm 2.8$ & $2.1 \pm 3.3$ & 0.23 & 0.21 & 0.80 \\
\hline $\begin{array}{l}\text { Leg pain postop } \pm \text { SD } \\
\text { (points) }\end{array}$ & $4.0 \pm 3.3$ & $4.1 \pm 3.2$ & $3.8 \pm 3.3$ & 1.0 & 1.0 & 0.62 \\
\hline $\begin{array}{l}\text { Leg pain relief } \pm S D \\
\text { (points) }\end{array}$ & $3.2 \pm 3.7$ & $3.2 \pm 3.2$ & $3.5 \pm 3.6$ & 1.0 & 1.0 & 0.54 \\
\hline $\begin{array}{l}\text { COMI score postop } \pm \text { SD } \\
\text { (points) }\end{array}$ & $4.7 \pm 2.8$ & $4.8 \pm 2.9$ & $4.5 \pm 3.0$ & 1.0 & 1.0 & 0.46 \\
\hline $\begin{array}{l}\text { COMI score change } \pm \text { SD } \\
\text { (points) }\end{array}$ & $2.9 \pm 2.9$ & $3.0 \pm 2.7$ & $3.2 \pm 3.0$ & 1.0 & 1.0 & 0.41 \\
\hline $\begin{array}{l}\text { Patient-reported } \\
\text { reoperations on the same } \\
\text { level }(\%)\end{array}$ & 2.9 & 2.0 & 2.4 & 1.0 & 1.0 & 1.0 \\
\hline Satisfied (\%) & 88.7 & 79.7 & 89.2 & 0.23 & 1.0 & 0.10 \\
\hline Not satisfied (\%) & 11.3 & 20.3 & 10.8 & & & \\
\hline Helped (\%) & 70.6 & 62.7 & 71.1 & 0.78 & 1.0 & 0.58 \\
\hline Did not help (\%) & 29.4 & 37.3 & 28.9 & & & \\
\hline $\begin{array}{l}\text { Length of hospital } \\
\text { stay } \pm \text { SD (days) }\end{array}$ & $4.9 \pm 4.6$ & $4.2 \pm 4.7$ & $3.6 \pm 3.7$ & 0.76 & $<0.001$ & 0.69 \\
\hline
\end{tabular}

Only weighted proportions and values are shown for raw proportions and values. Appendix 1

$D T$ durotomy, $S D$ standard deviation

Significant differences are written in bold

In relation to the experience of the surgeon, Sin et al. demonstrated that there was a higher risk of DT in surgeons in training [26]. In our study, however, surgeon experience did not influence DT rates.

Duration of surgery was significantly longer in patients with repaired DT compared with patients without DT. More than $27 \%$ of the patients with repaired DT had a duration of surgery $>2 \mathrm{~h}$, whereas only around $8 \%$ the patients in the other two groups had a duration of surgery that long. Desai et al. also found incidental DT to be associated with significantly longer surgery times regardless of repaired or not [19]. Patients with a DT in our study had inpatient stays that were on average 1 day longer than those without DT. Similar increases in the length of stay by 1.2 and 1.8 days on average were also reported by Desai et al. and Nandyala $[19,30]$. It has been argued that this makes the treatment of DT uneconomic [30].

\section{Influence of incidental durotomies on patient-rated outcome}

Patient satisfaction with treatment in the hospital and the global treatment outcome ratings did not differ significantly among the patient groups. However, the proportions of patients who were "not satisfied" and who reported a "poor global treatment outcome" were, respectively, 9 and 


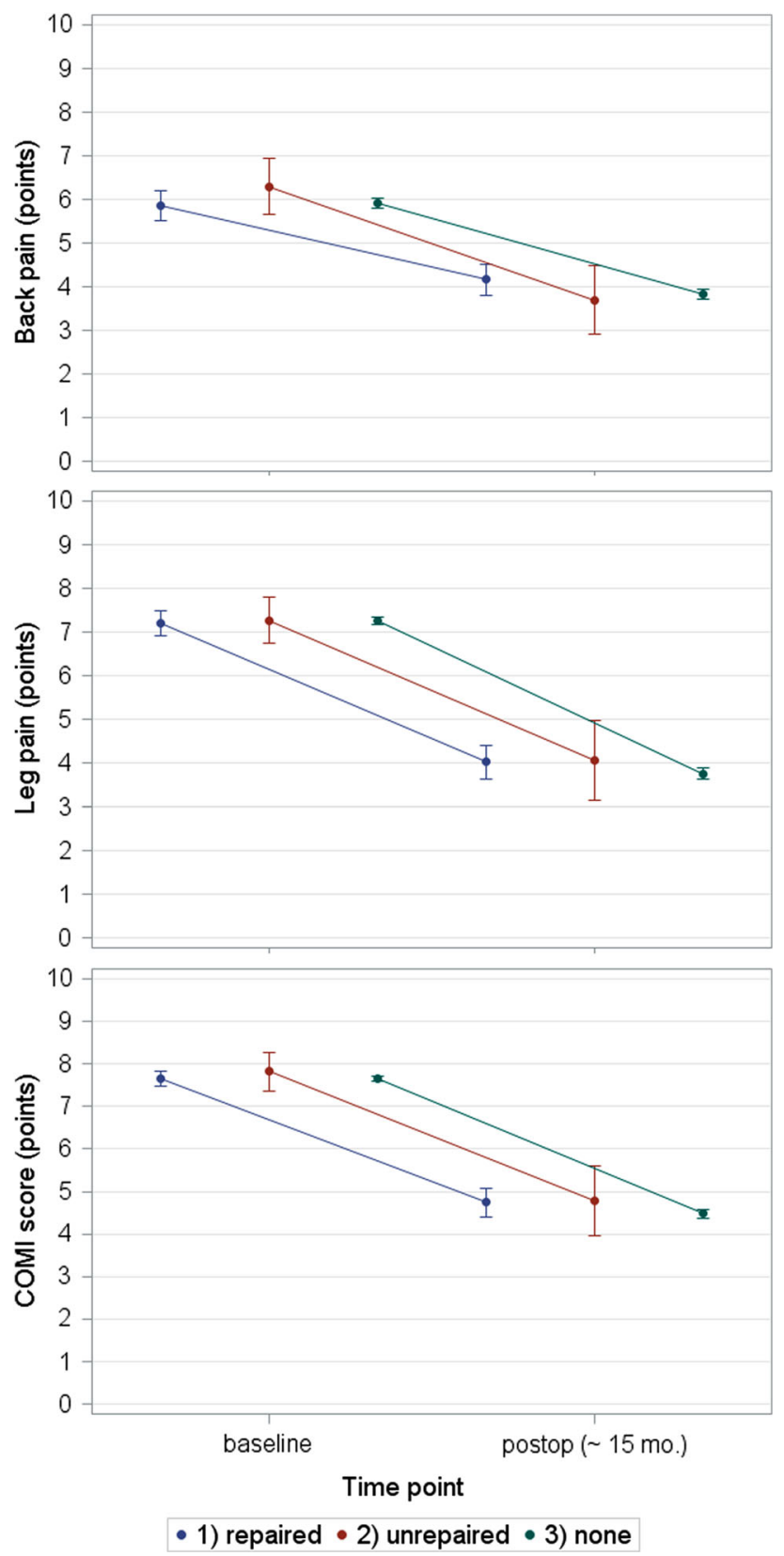

Fig. 3 Pain relief and improvement in COMI score in patients with no DT, repaired DT, and unrepaired DT, adjusted for case-mix

$8 \%$ higher in the unrepaired DT group than in either of the other groups. This results in numbers needed to treat (NNT) of 11 (95\% CI 6-97) and 13 (95\% CI 5-20), respectively. These NNTs may potentially be clinically relevant, as $\mathrm{NNT}=10$ is usually regarded as a cut-off for clinical relevance [23]. However, they should be confirmed in future studies with larger sample sizes, to obtain tighter confidence intervals. The reason why fewer patients with unrepaired DT were satisfied with their care is not obvious, considering the otherwise similar outcomes. The only observed significant difference between patients with repaired and those with unrepaired DT was in the duration of surgery. In almost $50 \%$ of the patients with unrepaired DT the duration of surgery was $<1 \mathrm{~h}$; in those with a repaired DT, surgery lasted $<1 \mathrm{~h}$ in just $18 \%$. In addition, a higher proportion of CSF leaks was seen in patients with unrepaired DT in comparison with repaired DT, although the difference was not statistically significant. It can be speculated that these two factors might have contributed to lower levels of satisfaction in those patients, perhaps due to the patients' perception that the operation did not proceed as well as expected.

The association between DT and patient outcome in LSS treatment is still debated. A matched study $(n=82)$ by Saxler et al. reported that patients with incidental DT had a tendency to report more back pain, were more likely to have further surgery, and had a longer return-to-work time after surgery [4]. Williams et al. reported a DT rate of $1.6 \%$ in 108,478 cases, and found an association between incidental DT and development of a new neurological deficit [24]. In a more recent study on 880 patients, Kothe et al. reported an association between incidental DT and an increase of patients' LOS, higher risk of re-intervention due to CSF leak and an inferior outcome in terms of leg pain after a 12 months follow-up [31]. However, Desai et al. reported no significant difference between DT and non-DT groups over a mean follow-up of 47.6 months in the SPORT data [19]. In a recent prospective multicenter study, Ulrich et al. also reported no effect of incidental DT on patient-rated outcomes after a follow-up of 24 months in a cohort of 167 patients [32]. In our international cohort, an incidental DT was not associated with the postoperative outcome in terms of leg and back pain relief and reduction in COMI score at the average follow-up of 15.4 months.

\section{Management of incidental durotomies}

Since there is ongoing discussion as to how to best manage incidental DTs, each surgeon tends to just use her/his own protocol, including choosing not to repair. A methodologically correct approach to evaluating the best management practice would involve randomization of DTs into repaired and unrepaired groups, but setting up such a study protocol is not feasible because it would be considered unethical to refuse a DT repair, since there are known, potentially dangerous complications of durotomies such as CSF leakage. However, observational registry data have the known limitation of hidden cause-effect relationships. We do not know why surgeons chose to repair DTs or close the wounds without repair. Thus can we only report on the association between DTs and outcomes using robust statistical methods.

We used the IPTW method to balance patient characteristics between patient groups to enable us to assess 
outcomes in a more unbiased way. This method mirrors some characteristics of randomized clinical trials and removes systematic differences between groups to a degree comparable to propensity score based matching (which is preferred when there are two groups only) [33]. As matching between more than two groups is not normal or simple, the IPTW was used. An important limitation of post hoc adjustment methods is that they cannot adjust for unobserved factors. In our analysis this means, for example, that we were not able to adjust for factors such as lesion size, location, and accessibility that might have led to the decision to repair the DT or not. Indeed, there are dural lesions that cannot be repaired in a watertight fashion. Nonetheless, twice as many potential confounders were considered in the present study in comparison with previous studies [7, 19].

In the Spine Tango data, the majority of DTs were repaired. Only $17 \%$ of all DTs were not, and these were documented in just seven out of the 21 centres. From this, it might be assumed that the management of DT is preference-based rather than being homogenously distributed between the participating centres. However, the total number of DTs occurring in each of the other 21 hospitals was only between 1 and 5, making any such conclusions difficult. By far the leading approach to DT repair, in $98.5 \%$ of cases across all the centres, was suture and/or the use of a fibrin glue (this characterization cannot be made more specific). Despite the multinational nature of this study and a putative lack of consensus about surgical management, these findings suggest surprisingly homogeneous management of incidental DTs.

Postoperative CSF leakage is a possible consequence of incidental DT. Therefore, a higher CSF leak rate in patients with DTs than in those without is not unexpected, although we saw early postoperative CSF leakage in two patients $(0.1 \%)$ with no record of DT. This was almost certainly related in each case to an unrecognised DT.

Patients with unrepaired DT differed from those with repaired DT in that they had a shorter duration of surgery. Additionally, a lower proportion of satisfied patients and patients with a good global treatment outcome, and a higher proportion of patients with CFS leaks were seen in this group, although the differences were not statistically significant and need to be evaluated in larger series of patients. Beyond these findings, no significant inter-group differences were found, including, in particular, no difference in patient-rated outcomes measured as pain relief and improvement in COMI score. This agrees with previous research [7, 19]. Limitations in this context were the study's overall follow-up rate of $48.4 \%$ and potentially also the small size of the group with unrepaired DT. However, one of the centres with a follow-up rate $>95 \%$ has already reported no significant association between DT and patient- reported outcome [34]. Another limitation of the study is that we did not control for centres when we compared treatment outcomes in relation to DT (none vs. repaired vs. unrepaired DT), and outcome may have been confounded by centre.

\section{Conclusions}

The unadjusted rates of incidental DT during decompression for lumbar spinal stenosis are reasonably comparable across the treatment centres represented in the international Spine Tango registry. Higher patient age, obesity, previous surgery at the same spinal level, minimally/less invasive surgery, and laminectomy were associated with an increased likelihood of DT. Non-repair of DTs had no negative association with treatment outcome; however, the unrepaired DTs may have been those that were smaller in size. No significant associations between incidental DT and patient-reported outcomes were found.

Acknowledgements All the participants of the Spine Tango Register are acknowledged for their continuous contribution that makes it possible for us to conduct such studies reflecting the daily practice of spine surgeons. The data of the following centres were used (in alphabetic order of country, city, hospital and department): Department of Spinal Surgery in Royal Adelaide Hospital (Australia); Department of Spinal Surgery in St. Andrew's Hospital in Adelaide (Australia); Department of Orthopaedic Surgery in Grand Hôpital de Charleroi (Belgium); Department of Orthopaedic Surgery in Edith Cavell Clinic of Brussels (Belgium); Department of Orthopaedic Surgery in University Hospital of St. Luc (Belgium); Department of Orthopaedic Surgery in Saint Pierre Clinic of Ottignies (Belgium); Department of Neurosurgery in University Hospital of Cologne (Germany); Department of Orthopaedic Surgery and Traumatology in University Hospital of Cologne (Germany); Group Practice of Orthopaedics and Neurosurgery in Hof (Germany); Department of Spine Surgery in Krankenhaus der Barmherzigen Brüder in Trier (Germany); Department of Orthopedic Surgery in Orthopedic and Traumatological Clinic Poznan (Poland); Department of Neurosurgery in Specialized Medical Center S.A. Polanica (Poland); Department of Neurosurgery in Medical University Silesia (Poland); Department of Neurosurgery in Hospital São João in Porto (Portugal); Department of Neurosurgery in Bethesda Hospital of Basel (Switzerland); Department of Neurosurgery in University Hospital of Bern (Switzerland); Department of Spine Surgery in University Hospital of Bern (Switzerland); Department of Orthopaedic Surgery in Salem Hospital of Bern (Switzerland); Department of Orthopaedic Surgery in Cantonal Hospital of Fribourg (Switzerland); Department of Neurosurgery in Clinique Générale of Fribourg (Switzerland); Department of Neurosurgery and Spine Surgery in St. Anna Clinic in Lucerne (Switzerland); Department of Orthopaedic Surgery and Traumatology in Cantonal Hospital of St. Gallen (Switzerland); Department of Spine Surgery in The Spine Center Thun (Switzerland); Spine Center Division in Schulthess Clinic of Zurich (Switzerland); Spine Unit of Nuffield Oxford Centre (UK); Department of Neurosurgery in Salford Royal NHS Foundation Trust (UK); Department of Spine Surgery in Salford Royal NHS Foundation Trust (UK); Department of Neurosurgery in The Walton Centre (UK); Department of Spine Surgery of Christiana Care Hospital in Newark, Delaware (USA). 


\section{Compliance with ethical standards}

Conflict of interest The authors have nothing to disclose.

\section{References}

1. Sobottke R, Herren C, Siewe J, Mannion AF, Roder C, Aghayev E (2017) Predictors of improvement in quality of life and pain relief in lumbar spinal stenosis relative to patient age: a study based on the Spine Tango registry. Eur Spine J 26:462-472. doi: 10.1007/s00586-015-4078-8

2. Kalevski SK, Peev NA, Haritonov DG (2010) Incidental dural tears in lumbar decompressive surgery: incidence, causes, treatment, results. Asian J Neurosurg 5:54-59

3. Tafazal SI, Sell PJ (2005) Incidental durotomy in lumbar spine surgery: incidence and management. Eur Spine J 14:287-290. doi:10.1007/s00586-004-0821-2

4. Saxler G, Kramer J, Barden B, Kurt A, Pfortner J, Bernsmann K (2005) The long-term clinical sequelae of incidental durotomy in lumbar disc surgery. Spine (Phila Pa 1976) 30:2298-2302

5. Munting E, Roder C, Sobottke R, Dietrich D, Aghayev E, Spine Tango C (2015) Patient outcomes after laminotomy, hemilaminectomy, laminectomy and laminectomy with instrumented fusion for spinal canal stenosis: a propensity score-based study from the Spine Tango registry. Eur Spine J 24:358-368. doi:10. 1007/s00586-014-3349-0

6. Desai A, Ball PA, Bekelis K, Lurie J, Mirza SK, Tosteson TD, Weinstein JN (2015) SPORT: does incidental durotomy affect longterm outcomes in cases of spinal stenosis? Neurosurgery 76(Suppl 1):S57-S63. doi:10.1227/01.neu.0000462078.58454.f4

7. Stromqvist F, Jonsson B, Stromqvist B (2012) Dural lesions in decompression for lumbar spinal stenosis: incidence, risk factors and effect on outcome. Eur Spine J 21:825-828. doi:10.1007/ s00586-011-2101-2

8. Baker GA, Cizik AM, Bransford RJ, Bellabarba C, Konodi MA, Chapman JR, Lee MJ (2012) Risk factors for unintended durotomy during spine surgery: a multivariate analysis. Spine J 12:121-126. doi:10.1016/j.spinee.2012.01.012

9. Burks CA, Werner BC, Yang S, Shimer AL (2015) Obesity is associated with an increased rate of incidental durotomy in lumbar spine surgery. Spine (Phila Pa 1976) 40:500-504. doi:10. 1097/brs.0000000000000784

10. Deyo RA, Cherkin DC, Loeser JD, Bigos SJ, Ciol MA (1992) Morbidity and mortality in association with operations on the lumbar spine. The influence of age, diagnosis, and procedure. J Bone Jt Surg Am 74:536-543

11. Shaffrey CI, Spotnitz WD, Shaffrey ME, Jane JA (1990) Neurosurgical applications of fibrin glue: augmentation of dural closure in 134 patients. Neurosurgery 26:207-210

12. Jankowitz BT, Atteberry DS, Gerszten PC, Karausky P, Cheng BC, Faught R, Welch WC (2009) Effect of fibrin glue on the prevention of persistent cerebral spinal fluid leakage after incidental durotomy during lumbar spinal surgery. Eur Spine J 18:1169-1174. doi:10.1007/s00586-009-0928-6

13. Khan MH, Rihn J, Steele G, Davis R, Donaldson WF 3rd, Kang JD, Lee JY (2006) Postoperative management protocol for incidental dural tears during degenerative lumbar spine surgery: a review of 3,183 consecutive degenerative lumbar cases. Spine (Phila Pa 1976) 31:2609-2613. doi:10.1097/01.brs.0000241066. 55849.41

14. Espiritu MT, Rhyne A, Darden BV 2nd (2010) Dural tears in spine surgery. J Am Acad Orthop Surg 18:537-545

15. Song Y, Li S, Song B, Zhang Y, Gao W, Li N, Fan K, Ma J (2014) The pathological changes in the spinal cord after dural tear with and without autologous fascia repair. Eur Spine $\mathbf{J}$ 23:1531-1540. doi:10.1007/s00586-014-3326-7

16. Epstein NE (2007) The frequency and etiology of intraoperative dural tears in 110 predominantly geriatric patients undergoing multilevel laminectomy with noninstrumented fusions. J Spinal Disord Tech 20:380-386. doi:10.1097/BSD.0b013e31802dabd2

17. Cammisa FP Jr, Girardi FP, Sangani PK, Parvataneni HK, Cadag S, Sandhu HS (2000) Incidental durotomy in spine surgery. Spine (Phila Pa 1976) 25:2663-2667

18. Sporns PB, Zimmer S, Hanning U, Zoubi T, Wolfer J, Herbort M, Schwindt W, Niederstadt T (2015) Acute tonsillar cerebellar herniation in a patient with traumatic dural tear and VAC therapy after complex trauma. Spine J 15:e13-e16. doi:10.1016/j.spinee. 2015.04.025

19. Desai A, Ball PA, Bekelis K, Lurie J, Mirza SK, Tosteson TD, Weinstein JN (2011) SPORT: does incidental durotomy affect long-term outcomes in cases of spinal stenosis? Neurosurgery 69:38-44. doi:10.1227/NEU.0b013e3182134171

20. von Elm E, Altman DG, Egger M, Pocock SJ, Gotzsche PC, Vandenbroucke JP, Initiative S (2007) The Strengthening the Reporting of Observational Studies in Epidemiology (STROBE) statement: guidelines for reporting observational studies. Bull World Health Organ 85:867-872

21. Melloh M, Staub L, Aghayev E, Zweig T, Barz T, Theis JC, Chavanne A, Grob D, Aebi M, Roeder C (2008) The international spine registry SPINE TANGO: status quo and first results. Eur Spine J 17:1201-1209. doi:10.1007/s00586-008-0665-2

22. Mannion AF, Porchet F, Kleinstuck FS, Lattig F, Jeszenszky D, Bartanusz V, Dvorak J, Grob D (2009) The quality of spine surgery from the patient's perspective. Part 1: The Core Outcome Measures Index in clinical practice. Eur Spine J 18(Suppl 3):367-373. doi:10.1007/s00586-009-0942-8

23. Staub LP, Ryser C, Roder C, Mannion AF, Jarvik JG, Aebi M, Aghayev E (2016) Total disc arthroplasty versus anterior cervical interbody fusion: use of the Spine Tango registry to supplement the evidence from randomized control trials. Spine J 16:136-145. doi:10.1016/j.spinee.2015.11.056

24. Williams BJ, Sansur CA, Smith JS, Berven SH, Broadstone PA, Choma TJ, Goytan MJ, Noordeen HH, Knapp DR Jr, Hart RA, Zeller RD, Donaldson WF 3rd, Polly DW Jr, Perra JH, BoachieAdjei O, Shaffrey CI (2011) Incidence of unintended durotomy in spine surgery based on 108,478 cases. Neurosurgery 68:117-124. doi:10.1227/NEU.0b013e3181fcf14e

25. Adam D, Papacocea T, Iliescu R (2015) Incidental durotomy in lumbar spine surgery-incidence, risk factors and management. Romanian Neurosurg 22:20-26

26. Sin AH, Caldito G, Smith D, Rashidi M, Willis B, Nanda A (2006) Predictive factors for dural tear and cerebrospinal fluid leakage in patients undergoing lumbar surgery. J Neurosurg Spine 5:224-227. doi:10.3171/spi.2006.5.3.224

27. Teli M, Lovi A, Brayda-Bruno M, Zagra A, Corriero A, Giudici F, Minoia L (2010) Higher risk of dural tears and recurrent herniation with lumbar micro-endoscopic discectomy. Eur Spine J 19:443-450. doi:10.1007/s00586-010-1290-4

28. Du JY, Aichmair A, Kueper J, Lam C, Nguyen JT, Cammisa FP, Lebl DR (2014) Incidental durotomy during spinal surgery: a multivariate analysis for risk factors. Spine (Phila Pa 1976) 39:E1339-1345. doi:10.1097/BRS.0000000000000559

29. Grannum S, Patel MS, Attar F, Newey M (2014) Dural tears in primary decompressive lumbar surgery. Is primary repair necessary for a good outcome? Eur Spine J 23:904-908. doi:10.1007/ s00586-013-3159-9

30. Nandyala SV, Elboghdady IM, Marquez-Lara A, Noureldin MN, Sankaranarayanan S, Singh K (2014) Cost analysis of incidental durotomy in spine surgery. Spine (Phila Pa 1976) 39:E1042-1051. doi:10.1097/brs.0000000000000425 
31. Kothe R, Quante M, Engler N, Heider F, Kneissl J, Pirchner S, Siepe C (2016) The effect of incidental dural lesions on outcome after decompression surgery for lumbar spinal stenosis: results of a multi-center study with 800 patients. Eur Spine J. doi:10.1007/ s00586-016-4571-8

32. Ulrich NH, Burgstaller JM, Brunner F, Porchet F, Farshad M, Pichierri G, Steurer J, Held U (2016) The impact of incidental durotomy on the outcome of decompression surgery in degenerative lumbar spinal canal stenosis: analysis of the Lumbar Spinal Outcome Study (LSOS) data - a Swiss prospective multi-center cohort study. BMC Musculoskelet Disord 17:170. doi:10.1186/ s12891-016-1022-y

33. Austin PC (2011) An introduction to propensity score methods for reducing the effects of confounding in observational studies. Multivar Behav Res 46:399-424. doi:10.1080/00273171.2011.568786

34. Mannion AF, Fekete TF, O'Riordan D, Porchet F, Mutter UM, Jeszenszky D, Lattig F, Grob D, Kleinstueck FS (2013) The assessment of complications after spine surgery: time for a paradigm shift? Spine J 13:615-624. doi:10.1016/j.spinee.2013. 01.047 